\title{
Fabrication and engineering of Ru local structures toward enhanced kinetics of hydrogen generation
}

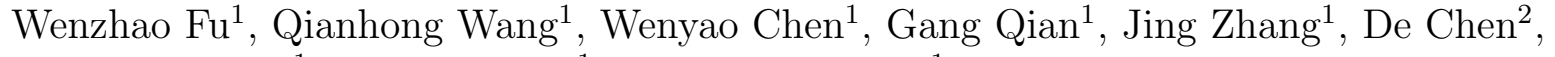 \\ Wei-Kang Yuan ${ }^{1}$, Xinggui Zhou ${ }^{1}$, and Xuezhi Duan ${ }^{1}$ \\ ${ }^{1}$ East China University of Science and Technology \\ ${ }^{2}$ Norges teknisk-naturvitenskapelige universitet
}

September 2, 2020

\begin{abstract}
A strategy to boost hydrogen generation from ammonia borane hydrolysis was proposed by engineering Ru local structures via the employment of $\mathrm{Cl}$-free $\mathrm{Ru}$ precursors and acid-leaching of the bimetallic $\mathrm{Ru}$-Co catalysts. The effects of $\mathrm{Cl}$ and $\mathrm{Co}$ were separately investigated by comparing the $\mathrm{Cl}$-free/Cl-containing monometallic Ru catalysts and Co-leaching/Co-containing bimetallic Ru-Co catalysts, respectively. Decoupled from the Co electronic effects (electron transfer from $\mathrm{Co}$ to $\mathrm{Ru}$ ), the $\mathrm{Cl}$ geometric effects (site blockage and steric hindrance) were identified as the main factors, which could be further promoted by introducing more low-coordinated Ru sites. The increase of Co content gives rise to more edge-like Ru active sites after acid leaching, with a lower $\mathrm{H} 2 \mathrm{O}$ activation barrier for hydrogen production. Consequently, al-Ru1Co with the most edge-like $\mathrm{Ru}$ active sites demonstrated a 4.1-fold increase in catalytic activity. The insights revealed here might guide the design and preparation of metal catalysts with the maximum active sites.
\end{abstract}

Fabrication and engineering of Ru local structures toward enhanced kinetics of hydrogen generation

Wenzhao Fu, ${ }^{\mathrm{a}}$ Qianhong Wang, ${ }^{\mathrm{a}}$ Wenyao Chen, ${ }^{\mathrm{a},{ }^{*}}$ Gang Qian, ${ }^{\mathrm{a}}$ Jing Zhang, ${ }^{\mathrm{a}}$ De Chen, ${ }^{\mathrm{b}}$ Weikang Yuan, ${ }^{\mathrm{a}}$ Xinggui Zhou, ${ }^{\mathrm{a}}$ Xuezhi Duan ${ }^{\mathrm{a},{ }^{,}}$

${ }^{a}$ State Key Laboratory of Chemical Engineering, East China University of Science and Technology, 130 Meilong Road, Shanghai 200237, China

${ }^{b}$ Department of Chemical Engineering, Norwegian University of Science and Technology, N-7491 Trondheim, Norway

${ }^{*}$ To whom correspondence should be addressed. Tel.: +86-21-64250937; E-mail: wenyao.chen@ecust.edu.cn; xzduan@ecust.edu.cn.

Abstract A strategy to boost hydrogen generation from ammonia borane hydrolysis was proposed by engineering $\mathrm{Ru}$ local structures via the employment of $\mathrm{Cl}$-free $\mathrm{Ru}$ precursors and acid-leaching of the bimetallic $\mathrm{Ru}-\mathrm{Co}$ catalysts. The effects of $\mathrm{Cl}$ and $\mathrm{Co}$ were separately investigated by comparing the $\mathrm{Cl}$-free/Clcontaining monometallic $\mathrm{Ru}$ catalysts and Co-leaching/Co-containing bimetallic Ru-Co catalysts, respectively. Decoupled from the Co electronic effects (electron transfer from Co to $\mathrm{Ru}$ ), the $\mathrm{Cl}$ geometric effects (site blockage and steric hindrance) were identified as the main factors, which could be further promoted by introducing more low-coordinated $\mathrm{Ru}$ sites. The increase of Co content gives rise to more edge-like $\mathrm{Ru}$ active sites after acid leaching, with a lower $\mathrm{H}_{2} \mathrm{O}$ activation barrier for hydrogen production. Consequently, al- $\mathrm{Ru}_{1} \mathrm{Co}$ with the most edge-like $\mathrm{Ru}$ active sites demonstrated a 4.1 -fold increase in catalytic activity. The 
insights revealed here might guide the design and preparation of metal catalysts with the maximum active sites.

Keywords: local structure; hydrogen generation; active sites; geometric and electronic effects; acid leaching.

\section{Introduction}

Hydrogen appears to be one of the most promising and renewable energy sources to the energy and environmental crises, while the efficient and safe hydrogen storage and production are the main technological obstacles in establishing a hydrogen-powered society ${ }^{1-5}$. Ammonia borane $\left(\mathrm{NH}_{3} \mathrm{BH}_{3}, \mathrm{AB}\right)$, owing to its high hydrogen content (19.6 wt\%), long-term stability and nontoxicity at room temperature, has been regarded as a potential hydrogen storage material ${ }^{6-9}$. Typically, the hydrogen stored in ammonia borane can be released by either pyrolysis or hydrolysis ${ }^{10-12}$. Although pyrolysis enables the regeneration of ammonia borane after usage, it is plagued by the requirement for high temperatures and the sluggish kinetics of hydrogen production ${ }^{13-15}$. By contrast, hydrolysis provides a fast hydrogen generation rate at mild conditions under proper catalysts, rendering it more appealing for practical application ${ }^{16-18}$. Hence, continuous efforts have been devoted to design and fabricate highly efficient catalysts to improve hydrolysis efficiency.

Various types of catalysts, including noble metals (e.g., $\mathrm{Ru}, \mathrm{Pt}, \mathrm{Rh}, \mathrm{Pd}$ and $\mathrm{Au}$ ) and nonnoble metals (Fe, $\mathrm{Co}, \mathrm{Ni}$ and $\mathrm{Cu}$ ), have been evaluated for the hydrolysis of ammonia borane, among which $\mathrm{Ru}$ - and Pt-based catalysts show the highest catalytic activity ${ }^{19-23}$. Considering their limited abundance and high cost, it still remains challenging yet highly desirable to further improve their catalytic activity and minimize their usage. Exemplified by Ru catalysts, strategies have been proposed to tune the electronic properties of active site and the resultant catalytic activity by: (i) introducing multi-metallic components with different structures ${ }^{24,25}$, such as alloys and core-shells, (ii) creating Ru-ligand interfacial bonding interactions based on the electronwithdrawing/donating properties ${ }^{26,27}$, (iii) constructing $\mathrm{Ru}$-support interactions by varying the identity and properties of the support ${ }^{28,29}$, and (iv) taking the advantage of confinement within porous organic cages and zeolites $^{30,31}$. As a result, significant improvements in the active site reactivity, that is, turnover frequency (TOF), have been recently achieved for this reaction.

As known, metal catalyst surfaces typically compose of abundant active sites working together as an ensemble for chemicals conversion, which the resultant catalytic performance is determined by both the quality (TOF) and quantity $(\mathrm{N})$ of active site, i.e., $\mathrm{r}=\mathrm{TOF} \times \mathrm{N}$. Based on this, apart from the above strategies to increase the TOF, the catalytic activity can be further improved by maximizing the quantity of active sites, N. However, it is worth to note that the traditional downsizing metal particles methods are not usually effective because not all of the surface atoms are active ${ }^{32,33}$. Hence, the identification of $\mathrm{Ru}$ active sites has emerged as a prerequisite for increasing the quantity of Ru active sites, which enables synergy between the quality and quantity of $\mathrm{Ru}$ active sites for this reaction. In our recent work, the Ru edge site has been identified as the main active site based on morphology characterization, particle modeling and kinetic analysis, providing a good opportunity for designing highly efficient $\mathrm{Ru}$ catalysts ${ }^{34}$. However, to the best of our knowledge, few studies have been conducted on tuning the quantity of Ru active site for ammonia borane hydrolysis, possibly due to the lack of knowledge about $\mathrm{Ru}$ active site. In this regard, it is highly desirable to gain a fundamental understanding of the $\mathrm{Ru}$ active site in terms of its local and electronic structure to fine-tune the quantity and quality of $\mathrm{Ru}$ active sites to promote hydrogen production.

In this work, we report a strategy to boost the quantity and quality of Ru active sites by employing a $\mathrm{Cl}$-free $\mathrm{Ru}$ precursor and the acid leaching of bimetallic Ru-Co catalysts, giving rise to a 4.1-fold increment in hydrogen generation rate from ammonia borane. Excluding the size effect, a series of Cl-free bimetallic $\mathrm{RuCo} / \mathrm{CNT}$ catalysts with different Co loadings were prepared and tested for this reaction and were compared with the $\mathrm{Cl}$-containing monometallic $\mathrm{Ru} \mathrm{Cl} / \mathrm{CNT}$ catalyst. The effects of $\mathrm{Cl}$ and $\mathrm{Co}$ on the $\mathrm{Ru}$ local structure were separately investigated by further comparing $\mathrm{Cl}$-free/Cl-containing monometallic $\mathrm{Ru}$ catalysts and Co-leaching/Co-containing bimetallic Ru-Co catalysts, respectively, based on the combination of multiple characterization techniques, kinetic (isotopic) analyses, and DFT calculations. Decoupled from the electronic effects (electron transfer), the geometric effects (site blockage and steric hindrance) of Ru were identified as 
the primary factors promoted by acid leaching to introduce more low-coordinated $\mathrm{Ru}$ active sites.

\section{Experimental}

\subsection{Catalyst preparation and testing}

Pristine multi-walled carbon nanotubes (CNT, purchased from Beijing Cnano Technology Limited) were employed as support to prepare the $\mathrm{Ru}$ and/or Co catalysts. Typically, a certain amount of CNT was mixed with an aqueous solution of $\mathrm{Ru}(\mathrm{NO})\left(\mathrm{NO}_{3}\right)_{3}$ (ruthenium(III) nitrosyl nitrate, Alfa Aesar) and/or $\mathrm{Co}(\mathrm{NO})_{3} \cdot 6 \mathrm{H}_{2} \mathrm{O}$ (Sinopharm Chemical Reagent Co. Ltd). The Ru loading was kept at $1.5 \mathrm{wt} \%$ for all the catalysts, and the molar ratio of $\mathrm{Ru}$ to $\mathrm{Co}$ was set as $3: 1,2: 1$ and 1:1. The as-prepared samples were placed at room temperature and then at $80{ }^{\circ} \mathrm{C}$ under stagnant air for $12 \mathrm{~h}$. Next, the catalyst precursors were reduced by pure $\mathrm{H}_{2}$ at $250{ }^{\circ} \mathrm{C}$ for $2 \mathrm{~h}$, followed by cooling to room temperature under Ar. To inhibit bulk oxidation, the as-obtained catalysts were further passivated by $1 \% \mathrm{O}_{2} / \mathrm{Ar}$ for another $20 \mathrm{~min}$. The catalysts were denoted as $\mathrm{Ru}_{3} \mathrm{Co} / \mathrm{CNT}, \mathrm{Ru}_{2} \mathrm{Co} / \mathrm{CNT}$ and $\mathrm{Ru}_{1} \mathrm{Co} / \mathrm{CNT}$. Acid leaching was conducted by mixing the bimetallic $\mathrm{RuCo} / \mathrm{CNT}$ catalysts $(0.5 \mathrm{~g})$ with $50 \mathrm{~mL}$ of dilute $\mathrm{HNO}_{3}(0.01 \mathrm{M})$ for $20 \mathrm{~min}$ at room temperature. The as-obtained catalysts were filtered, washed and dried at $80{ }^{\circ} \mathrm{C}$ for $12 \mathrm{~h}$, and denoted as al-Ru $\mathrm{H}_{3} \mathrm{Co} / \mathrm{CNT}$, $\mathrm{al}-\mathrm{Ru}_{2} \mathrm{Co} / \mathrm{CNT}$ and $\mathrm{al}-\mathrm{Ru}_{1} \mathrm{Co} / \mathrm{CNT}$.

\subsection{Catalytic testing}

The catalytic testing of these catalysts for ammonia borane hydrolysis was performed in a three-neck flask containing a magnetic stirrer. The flask was immersed in a water bath to control the reaction temperature at $25{ }^{\circ} \mathrm{C}$. Prior to the reaction, $0.05 \mathrm{~g}$ of catalyst was transferred into the flask, and the reaction was initiated by injecting an aqueous ammonia borane solution $\left(5 \mathrm{~mL}, 0.01 \mathrm{~g}[?] \mathrm{mL}^{-1}\right)$ into the flask with a stirring speed of $900 \mathrm{rpm}$. A glass gas burette filled with $\mathrm{H} 2 \mathrm{O}$ was connected to the reaction flask to record the amount of discharged $\mathrm{H} 2 \mathrm{O}$, which was weighed by an electronic balance and converted into the volume of evolved hydrogen. These catalysts were also used for ammonia borane hydrolysis at elevated temperatures $(30,35$ and $40 \operatorname{deg}$ ) to obtain the activation energy and pre-exponential factor. The kinetic isotopic experiments were performed by replacing $\mathrm{H}_{2} \mathrm{O}$ with $\mathrm{D}_{2} \mathrm{O}$ as the reactant under the same reaction conditions.

\subsection{Characterization}

The metal particle size distributions of the catalysts were determined by high-angle annular dark fieldscanning transmission electron microscopy (HAADF-STEM) on a Tecnai G2 F20 S-Twin microscopy. The catalyst morphologies were characterized by high-resolution transmission electron microscopy on a JEOL JSM-2100 electron microscopy operating at $200 \mathrm{kV}$. The electronic properties were characterized by X-ray photoelectron spectrometry (XPS) on a ThermoFisher ESCALAB250Xi equipped with an $\mathrm{Al} \mathrm{K}_{\alpha} \mathrm{X}$-ray $(1486.6 \mathrm{eV}$, excitation source working at $15 \mathrm{kV})$; the $\mathrm{C} 1 s$ peak at $284.6 \mathrm{eV}$ was used to calibrate the binding energy. The contents of $\mathrm{Ru}$ and $\mathrm{Co}$ within the spent acid solution were determined by inductively coupled plasma-atomic emission spectrometry (ICP-AES) on an Agilent 725-ES. $\mathrm{H}_{2}$-temperature-programmed reduction $\left(\mathrm{H}_{2}\right.$-TPR $)$ measurements were conducted on a Micrometrics Autochem 2920 chemisorption instrument equipped with a thermal conductivity detector.

\subsection{DFT calculation}

The DFT calculations were performed by VASP ${ }^{35-38}$ with the projected augmented wave (PAW) method ${ }^{39}$, and the exchange-correlation functional was generalized gradient approximation (GGA) with the PerdewBurke-Ernzerhof (PBE) method ${ }^{40}$. The Kohn-Sham orbitals were expanded in a plane-wave basis set with a kinetic cutoff energy of $450 \mathrm{eV}^{41}$. The sampling of the Brillouin zone was performed using a Monkhorst-Pack scheme. The equilibrium lattice constant of $\mathrm{a}=2.72 \AA$ and $\mathrm{c}=4.31 \AA$ are obtained for bulk $\mathrm{Ru}$ in the hcp structure, which agrees well with the experimental bulk lattice constant $(\mathrm{a}=2.71 \AA$ and $\mathrm{c}=4.28 \AA)$. The surface slabs of $\mathrm{Ru}(001), \mathrm{Ru}(101)$ and $\mathrm{Ru}(111)$ were respectively modeled with $\mathrm{p}(4 \times 4), \mathrm{p}(2 \times 4)$ and $\mathrm{p}(2$ $\times 2$ ) supercells with a vacuum region of $15 \AA$, where the bottom two-layer $\mathrm{Ru}$ atoms were fixed and the top two-layer $\mathrm{Ru}$ atoms were relaxed. For all the calculations, the geometry optimization was converged until the forces on each atom were less than $0.03 \mathrm{eV} / \AA$ and the total energy differences were less than $10^{-5} \mathrm{eV}$. 
The $\mathrm{H}_{2} \mathrm{O}$ activation energy was calculated as $\Delta \mathrm{E}_{\mathrm{a}}=\mathrm{E}_{\mathrm{TS}}-\mathrm{E}_{\mathrm{ads}}$, where the $\mathrm{E}_{\mathrm{TS}}$ is the energy of transition state (TS), the $\mathrm{E}_{\text {ads }}$ is the adsorption energy of $\mathrm{H}_{2} \mathrm{O}$. The $\mathrm{H}_{2} \mathrm{O}$ adsorption energy was calculated as $\mathrm{E}_{\text {ads }}$ $=\mathrm{E}_{\mathrm{H} 2 \mathrm{O} / \text { surface }}-\mathrm{E}_{\mathrm{H} 2 \mathrm{O}}-\mathrm{E}_{\text {surface }}$, where $\mathrm{E}_{\mathrm{H} 2 \mathrm{O} / \text { surface }}$ is the total energy of the surface adsorbed with $\mathrm{H}_{2} \mathrm{O}$, $\mathrm{E}_{\text {surface }}$ is the total energy of the clean surface, and $\mathrm{E}_{\mathrm{H} 2 \mathrm{O}}$ is the total energy of isolated $\mathrm{H}_{2} \mathrm{O}$. The Bader analysis was implemented with a fast algorithm, and the core charge density was included in the partitioning. The charge density difference images were obtained by VESTA visualization software.

\section{Results and discussion}

\subsection{Significantly improved hydrogen generation kinetics}

In light of the catalytic performance mainly determined by the metal local environment, both $\mathrm{Ru}(\mathrm{NO})\left(\mathrm{NO}_{3}\right)_{3}$ and $\mathrm{Co}(\mathrm{NO})_{3} \cdot 6 \mathrm{H}_{2} \mathrm{O}$ were used to prepare $\mathrm{Cl}$-free bimetallic $\mathrm{Ru}$-Co catalysts with different $\mathrm{Ru} / \mathrm{Co}$ ratios, i.e., $\mathrm{Ru}_{3} \mathrm{Co} / \mathrm{CNT}, \mathrm{Ru}_{2} \mathrm{Co} / \mathrm{CNT}$ and $\mathrm{Ru}_{1} \mathrm{Co} / \mathrm{CNT}$, with the aim of significantly altering the local structure of $\mathrm{Ru}$ atoms for this reaction. Considering that Ru-catalyzed ammonia borane hydrolysis has been suggested as a highly structure-sensitive reaction ${ }^{34}$, the particle sizes of these catalysts were first evaluated, prior to the catalytic testing. High-resolution HAADF-STEM was employed to characterize the particle size distribution of the catalysts. As shown in Figure S1, all three catalysts exhibited a relatively homogenous distribution of metal particles over the CNT surface. Based on the measurements of more than 200 random particles, the average metal particle sizes were determined to be $1.34 \pm 0.36,1.33 \pm 0.35$, and $1.40 \pm 0.37 \mathrm{~nm}$ for $\mathrm{Ru}_{3} \mathrm{Co} / \mathrm{CNT}$, $\mathrm{Ru}_{2} \mathrm{Co} / \mathrm{CNT}$, and $\mathrm{Ru}_{1} \mathrm{Co} / \mathrm{CNT}$, respectively. The metal particle size remained almost unchanged despite of the addition of $\mathrm{Co}$ to $\mathrm{Ru}$. This indicates that $\mathrm{Ru}$ can promote the distribution of Co and obtain the similarsized metal catalysts, which would help to minimize the effect of particle size and enable a fair comparison of the $\mathrm{Ru}$ local structure for this reaction.

With similar metal particle sizes, these three catalysts were tested for the hydrolytic dehydrogenation of ammonia borane under the same reaction conditions, and the results are shown in Figure S2. In the initial stage of reaction, all three catalysts exhibited a linear dependence between the hydrogen volume and the reaction time (ammonia borane conversion less than $45 \pm 5 \%$ ). Considering $\mathrm{H}_{2} \mathrm{O}$ in large excess, this suggests pseudo-zero order kinetics with respect to ammonia borane for this reaction. Hence, the corresponding initial hydrogen generation rate $\left(\mathrm{r}_{\text {initial }}\right)$ was calculated based on the slope of the linear part for each curve in Figure S2. In addition, the monometallic Co/CNT was also evaluated for this reaction and almost no activity was found, as shown in Figure S3. Figure 1a displays the catalytic activity of these catalysts, which the Cl-containing $\mathrm{Ru}_{\mathrm{Cl}} / \mathrm{CNT}$ catalysts from our previous study were also used as references for comparison. Obviously, there was a significant increase in catalytic activity for the $\mathrm{Cl}$-free bimetallic RuCo/CNT catalysts compared with the $\mathrm{Cl}$-containing monometallic $\mathrm{Ru}_{\mathrm{Cl}} / \mathrm{CNT}$ catalysts of similar particle size, especially for $\mathrm{Ru}_{1} \mathrm{Co} / \mathrm{CNT}$ with an $\mathrm{r}_{\text {initial }}$ of $667.7 \mathrm{~mol}_{\mathrm{H} 2} \cdot \mathrm{mol}_{\mathrm{Ru}} \cdot \mathrm{min}^{-1}$, which demonstrates a 3.6 -fold increment in catalytic activity. 

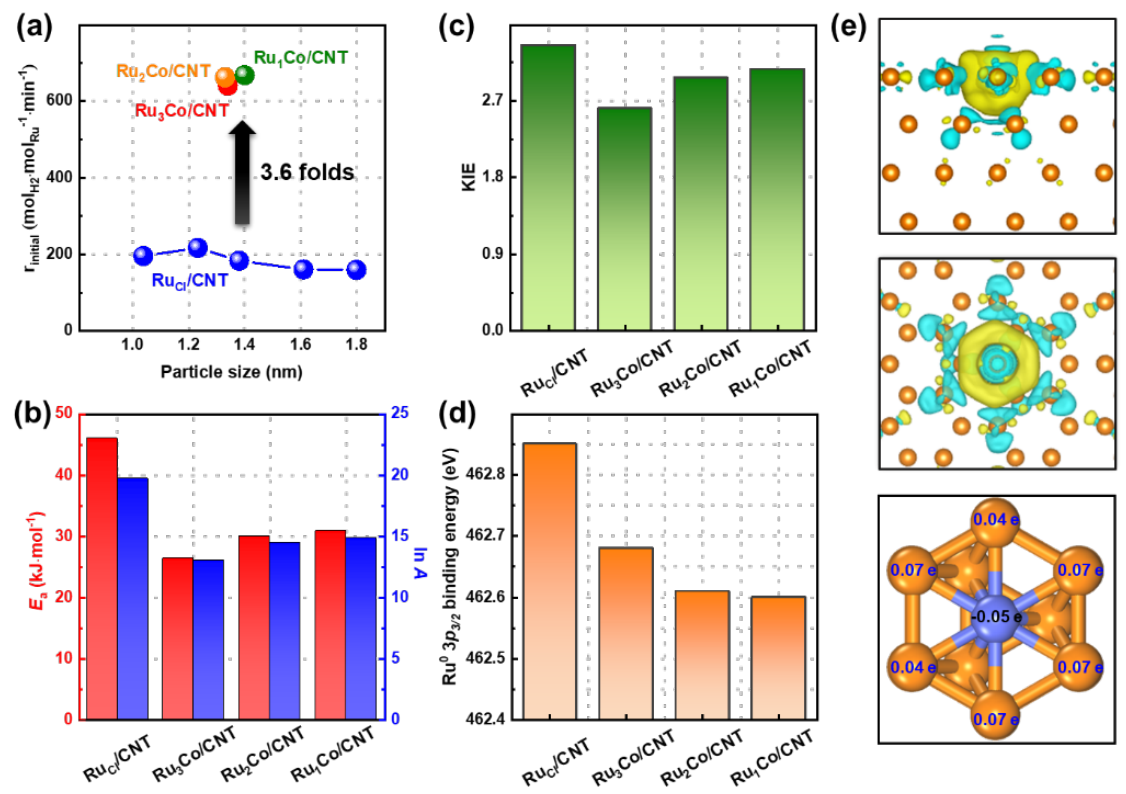

Figure 1. (a) The initial catalytic activity $\left(\mathrm{r}_{\text {initial }}\right)$, (b) activation energy $\left(E_{\text {a }}\right)$ and the logarithm of preexponential factor $(\ln A)$, (c) kinetic isotope effect (KIE) values, and (d) $\mathrm{Ru}^{0} 3 p_{3 / 2}$ binding energy of the $\mathrm{Ru}_{\mathrm{Cl}} / \mathrm{CNT}, \mathrm{Ru}_{3} \mathrm{Co} / \mathrm{CNT}, \mathrm{Ru}_{2} \mathrm{Co} / \mathrm{CNT}$, and $\mathrm{Ru}_{1} \mathrm{Co} / \mathrm{CNT}$ catalysts. The $\mathrm{Ru}$ loading for $\mathrm{Ru}_{\mathrm{Cl}} / \mathrm{CNT}$ was 1.5 wt\%. (e) The charge density difference and corresponding charge transfer of the RuCo catalyst. The yellow and light blue isosurfaces denote the electron increase and depletion zone, respectively.

To gain more insight, the catalysts were kinetically analyzed by varying the reaction temperature from 25 to $40{ }^{\circ} \mathrm{C}$, and the results are shown in Figure S2. The catalysts still retained a linear increase in hydrogen volume with reaction time in the initial stage (ammonia borane conversion less than $45 \pm 5 \%$ ), confirming the pseudo-zero order kinetics in this temperature range. Similarly, the reaction rate $(\mathrm{r})$ and rate constant $\left(k_{H}\right)$ were calculated, which further yielded the activation energy $\left(E_{a}\right)$ and the logarithm of pre-exponential factor $(\ln A)$ based on the corresponding Arrhenius plot. As shown in Figure 1b, the Cl-free bimetallic RuCo/CNT catalysts delivered much lower $E_{a}$ values compared with the Cl-containing monometallic $\mathrm{Ru}_{\mathrm{Cl}} / \mathrm{CNT}$ catalyst, consistent with the trend of catalytic activity. Moreover, there were slight increases in the $E_{a}$ for these Cl-free bimetallic $\mathrm{RuCo} / \mathrm{CNT}$ catalysts with the addition of $\mathrm{Co}$. Hence, $\mathrm{Ru}_{1} \mathrm{Co} / \mathrm{CNT}$, with the highest catalytic activity, showed a relatively higher $\mathrm{E}_{\mathrm{a}}$, indicating the effects of another important factor. Based on the Arrhenius equation, both the $E_{a}$ and $\ln A$ contribute to the reaction rate constant, as the representation of the activation $\left(\Delta \mathrm{H}^{0^{*}}\right)$ and adsorption $\left(\Delta \mathrm{S}^{0^{*}}\right)$ of reactants over the catalyst surface, respectively ${ }^{42-44}$. As shown in Figure 1b, the higher $\ln A$ of $\mathrm{Ru}_{1} \mathrm{Co} / \mathrm{CNT}$ corresponds to the lower loss of translational freedom upon reactant adsorption as a result of weaker interactions between the catalyst surface and reactants. This is consistent with our previous study ${ }^{43}$ that Ru locates at the left side of the volcanic curve owing to strong interactions with reactants, and weakening this interaction gives rise to higher catalytic activity.

Kinetic isotopic experiments replacing $\mathrm{H}_{2} \mathrm{O}$ with $\mathrm{D}_{2} \mathrm{O}$ as the reactant were also conducted to probe the underlying kinetic information. As shown in Figure S4, all these catalysts still displayed a linear increase in hydrogen volume with reaction time in the initial stage (ammonia borane conversion less than $45 \pm 5 \%$ ), but much slower hydrogen generation rate when using $\mathrm{D}_{2} \mathrm{O}$ as the reactant. Similarly, the corresponding reaction rate constant $\left(k_{D}\right)$ was calculated based on the slope of the linear part for each curve. As a result, the ratio of the reaction rate constant using $\mathrm{H}_{2} \mathrm{O}$ and $\mathrm{D}_{2} \mathrm{O}$ as reactant, that is, $k_{H} / k_{D}$, was calculated, which has been widely used to study the kinetic isotope effect (KIE). As shown in Figure 2c, the Cl-free bimetallic $\mathrm{RuCo} / \mathrm{CNT}$ catalysts delivered lower $\mathrm{KIE}$ values compared with the $\mathrm{Cl}$-containing monometallic $\mathrm{Ru}_{\mathrm{Cl}} / \mathrm{CNT}$ 
catalyst, which suggests that the presence of $\mathrm{Cl}$ may inhibit water activation. By contrast, further increasing Co loading gave rise to a relatively higher KIE value, in line with the activation energy trend in Figure 2b.

\subsection{Structural characterization}

High-resolution transmission electron microscopy (HRTEM) was first employed to probe the significantly improved hydrogen generation kinetics. As shown in Figure S5, it was clear that the Cl-free bimetallic Ru-Co catalysts exhibited the inter-spacings ranging from 0.213 to $0.209 \mathrm{~nm}$ and from 0.221 to $0.217 \mathrm{~nm}$, most likely attributed to the (002) and (100) facets of the RuCo alloy, respectively. $\mathrm{H}_{2}$-TPR measurement was conducted to characterize these catalysts. As shown in Figure S6, all these catalysts exhibited one main hydrogen consumption peak ascribed to the reduction of $\mathrm{Ru}$ species. Specifically, with respect to the Cl-containing monometallic $\mathrm{Ru}_{\mathrm{Cl}} / \mathrm{CNT}$ catalyst, the hydrogen reduction peak shifted from the higher temperature of 213 ${ }^{\circ} \mathrm{C}$ to lower temperatures for these $\mathrm{RuCo} / \mathrm{CNT}$ catalysts. Generally, the reduction temperature of a metal varies according to the interaction between the metal precursor and catalyst support. Hence, the observed decrease in reduction temperature indicates lower stability of the Cl-free $\mathrm{Ru}$ precursor, either intrinsically less stable or stabilized by the support. By contrast, the reduction peak gradually shifted to a relatively high temperature with the addition of $\mathrm{Co}$, attributed to the strong $\mathrm{Ru}$ and Co interactions. Notably, the absence of legible Co reduction peaks for these catalysts could be ascribed to the high dispersion of Co atoms within the Ru-Co alloy particles, which could be easily reduced by the spillover hydrogen from Ru sites.

XPS was further employed to characterize the electronic properties of these catalysts. As shown in Figure $\mathrm{S} 7$, the Cl-free bimetallic RuCo/CNT catalysts exhibited much stronger XPS peak intensities compared with the $\mathrm{Cl}$-containing monometallic $\mathrm{Ru}_{\mathrm{Cl}} / \mathrm{CNT}$ catalyst, possibly due to differences in the $\mathrm{Ru}$ precursor. The XPS Ru $3 p_{3 / 2}$ spectra was further deconvoluted into three $\mathrm{Ru}$ species, $\mathrm{Ru}^{0}, \mathrm{Ru}^{2+}$ and $\mathrm{Ru}^{4+}$, to gain a more detailed quantitative understanding. It was found that metallic $\mathrm{Ru}\left(\mathrm{Ru}^{0}\right)$ remained the primary $\mathrm{Ru}$ species for these catalysts. Interestingly, there was a downshift in Ru binding energy for these catalysts, as shown in Figure 1d, following the order of $\mathrm{Ru}_{\mathrm{Cl}} / \mathrm{CNT}(462.85 \mathrm{eV})>\mathrm{Ru}_{3} \mathrm{Co} / \mathrm{CNT}(462.65 \mathrm{eV})>\mathrm{Ru}_{2} \mathrm{Co} / \mathrm{CNT}$ $(462.61 \mathrm{eV})>\mathrm{Ru}_{1} \mathrm{Co} / \mathrm{CNT}(462.60 \mathrm{eV})$. Considering the similar metal particle size of these catalysts, the observed binding energy shift was mainly ascribed to electron transfer within the catalysts. Specifically, Co as an electron donor would transfer more electrons to $\mathrm{Ru}$ and gave rise to lower $\mathrm{Ru}$ binding energy. To verify this, DFT calculations were carried out to probe the electron transfer between $\mathrm{Ru}$ and Co. Figure 1e displays the 3D electron density of the Co-doped $\mathrm{Ru}(001)$ facet and showed increased electron density around the $\mathrm{Ru}$ atoms in comparison with decreased density around the Co atoms. As a result, the Ru charge based on Bader charge analysis was determined to be 0.07 e and $0.04 \mathrm{e}$, which is in line with the XPS results of the electron transfer from Co to $\mathrm{Ru}$.

Based on our previous study ${ }^{43}$, the monometallic $\mathrm{Ru}$ was found to be less active and located on the left side of the volcanic curve owing to the strong interactions with reactants, this is $\mathrm{Ru}^{+}-\mathrm{H}^{-}-\mathrm{BH}_{2} \mathrm{NH}_{3}$. To weak this interaction toward the top of the volcanic curve, it is necessary to increase the Ru electron density by lowering its binding energy. Hence, from an electronic properties point of view, the addition of Co could effectively lower the Ru binding energy, which should give rise to increased catalytic activity. In this regard, a correlation between the $\mathrm{Ru}^{0} 3 p_{3 / 2}$ binding energy and $\mathrm{r}_{\text {initial }}$ was made as shown in Figure 2 . The catalytic activity of these catalysts exhibited a sharp increase and followed two linear relationships with the $\mathrm{Ru}^{0} 3 p_{3 / 2}$ binding energy for which the amplitude of variation induced by $\mathrm{Cl}$ was much more significant than that induced by Co. This suggested that, apart from the electronic effects, other effects (e.g., geometric effects) induced by $\mathrm{Cl}$ may significantly contribute to the improved catalytic activity when using the $\mathrm{Cl}$-free $\mathrm{Ru}$ precursor. 


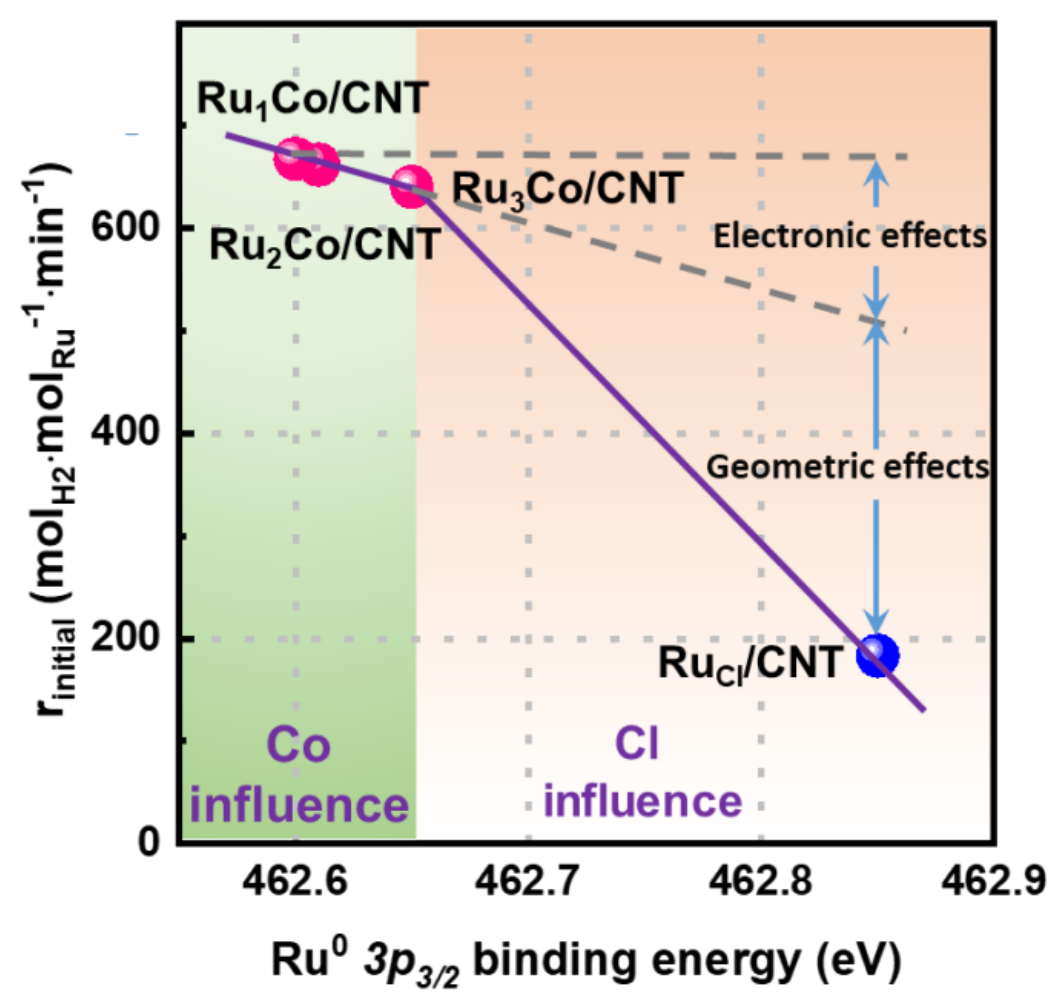

Figure 2. The relationship between $\mathrm{r}_{\text {initial }}$ and the $\mathrm{Ru}^{0} 3 p_{3 / 2}$ binding energy for the $\mathrm{Ru} \mathrm{Cl} / \mathrm{CNT}$, $\mathrm{Ru}_{3} \mathrm{Co} / \mathrm{CNT}, \mathrm{Ru}_{2} \mathrm{Co} / \mathrm{CNT}$, and $\mathrm{Ru}_{1} \mathrm{Co} / \mathrm{CNT}$ catalysts. The Ru loading for $\mathrm{Ru}_{\mathrm{Cl}} / \mathrm{CNT}$ was $1.5 \mathrm{wt} \%$.

\subsection{Decoupling the electronic and geometric effects}

To better illustrate the influence of $\mathrm{Cl}$, DFT calculations were first carried out to investigate the adsorption of $\mathrm{Cl}$ and its results on three representative $\mathrm{Ru}$ facets, $\mathrm{Ru}(001), \mathrm{Ru}(101)$ and $\mathrm{Ru}(111)$. The electron density around $\mathrm{Cl}$ was obviously depleted for these three facets, and $\mathrm{Cl}$ as an electron donor to transfers electrons to $\mathrm{Ru}$. As a result, the Bader charge analysis suggests that the $\mathrm{Ru}(001), \mathrm{Ru}(101)$ and $\mathrm{Ru}(111)$ facets capture $0.53 \mathrm{e}, 0.54 \mathrm{e}$ and $0.48 \mathrm{e}$ from $\mathrm{Cl}$, respectively. Hence, the electron-rich $\mathrm{Ru}$ is inconsistent with its low catalytic activity, which indicates that the electronic effects are not the main reason for the significant improvement seen when using a $\mathrm{Cl}$-free $\mathrm{Ru}$ precursor. Moreover, Figure 3a shows that these three facets exhibit strong $\mathrm{Cl}$ adsorption, especially for the stepped $\mathrm{Ru}(111)$ facet with an adsorption energy of $3.43 \mathrm{eV}$. Considering that the $\mathrm{Ru}$ edge site was identified as the main active site for this reaction, the strongest adsorption of $\mathrm{Cl}$ on the edge-like $\mathrm{Ru}(111)$ facet indicates the severe blockage and significant loss of $\mathrm{Ru}$ active sites. 

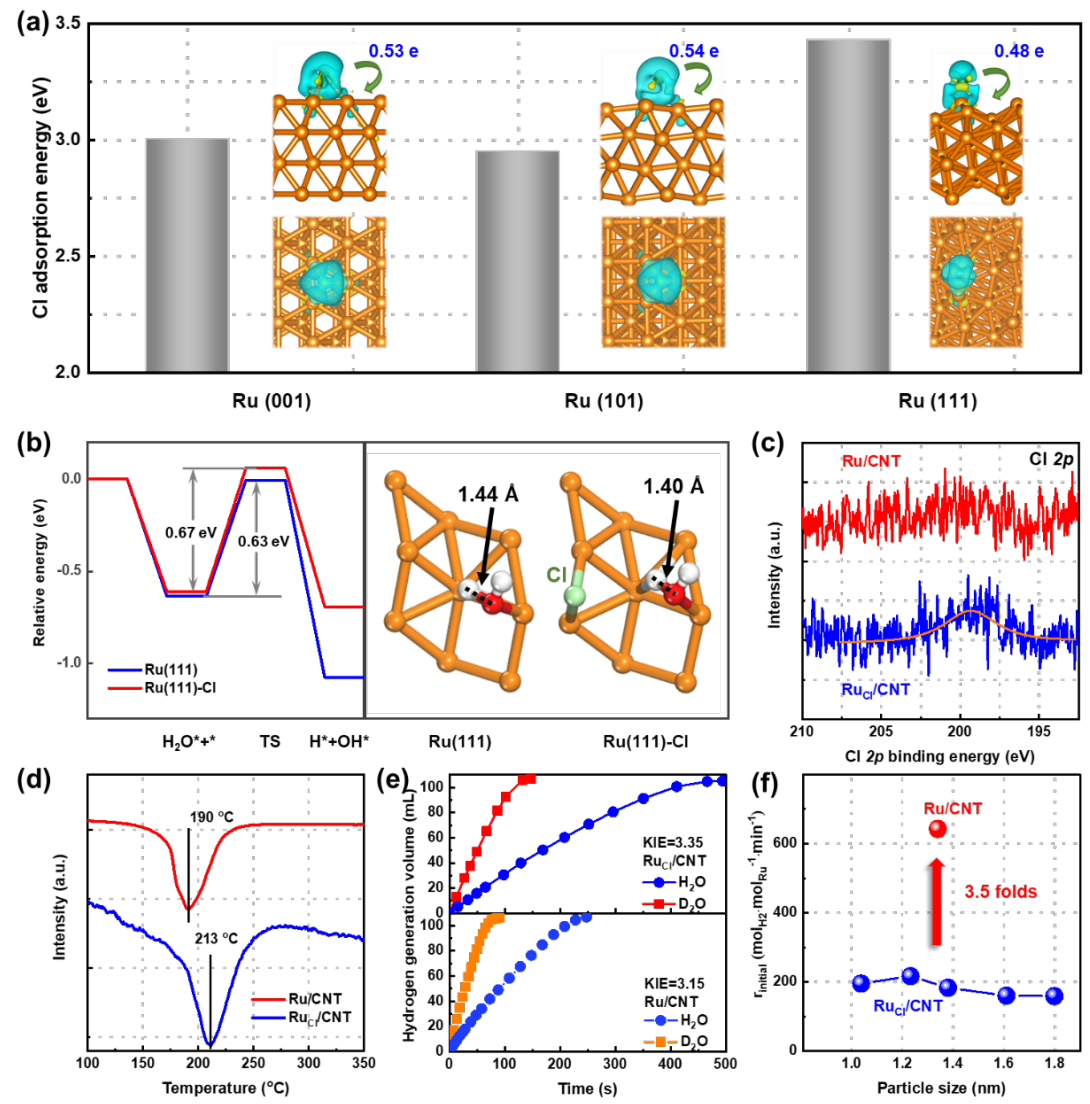

Figure 3. (a) The adsorption energy of $\mathrm{Cl}$ and corresponding isosurfaces of the differential electron density for $\mathrm{Cl}$ on the $\mathrm{Ru}(001), \mathrm{Ru}(101)$ and $\mathrm{Ru}(111)$ facets. The yellow and light blue isosurfaces correspond to the zones of electron increase and depletion, respectively. (b) The energy profiles and corresponding structures of transition states for $\mathrm{H}_{2} \mathrm{O}$ activation over the $\mathrm{Ru}(111)$ and $\mathrm{Ru}(111)-\mathrm{Cl}$ facets. (c) The XPS Cl $2 p$ spectra, (d) $\mathrm{H}_{2}$-TPR profiles, (e) hydrogen generation volume as a function of reaction time using $\mathrm{H}_{2} \mathrm{O}$ and $\mathrm{D}_{2} \mathrm{O}$ as reactant, and (f) initial catalytic activity $\left(\mathrm{r}_{\text {initial }}\right)$ for the $\mathrm{Ru}_{\mathrm{Cl}} / \mathrm{CNT}$ and $\mathrm{Ru} / \mathrm{CNT}$ catalysts. The $\mathrm{Ru}$ loading for $\mathrm{Ru}_{\mathrm{Cl}} / \mathrm{CNT}$ was $1.5 \mathrm{wt} \%$.

Furthermore, the influence of $\mathrm{Cl}$ adsorption on the neighboring $\mathrm{Ru}$ active site was also studied. Considering the substantial kinetic isotope effect (KIE), as shown in Figure 1c, the adsorption and activation of $\mathrm{H}_{2} \mathrm{O}$ on $\mathrm{Ru}(111)$ and $\mathrm{Cl}$-doped $\mathrm{Ru}(111)$, that is, the $\mathrm{Ru}(111)$-Cl facet, were comparatively investigated through $\mathrm{DFT}$ calculations. Figure S8 displays the optimized most stable adsorption configurations of the involved species on the $\mathrm{Ru}(111)$ and $\mathrm{Ru}(111)-\mathrm{Cl}$ surfaces, and the corresponding potential energy profiles are displayed in Figure $3 \mathrm{~b}$. The adsorption energy of $\mathrm{H}_{2} \mathrm{O}$ on the $\mathrm{Ru}(111)$ surface was higher than that on the $\mathrm{Ru}(111)-\mathrm{Cl}$ surface. As a result, the energy barrier for $\mathrm{H}_{2} \mathrm{O}$ activation on the $\mathrm{Ru}(111)$ and $\mathrm{Ru}(111)-\mathrm{Cl}$ surfaces were calculated to be 0.63 and $0.67 \mathrm{eV}$, respectively. This indicates that the $\mathrm{Ru}(111)-\mathrm{Cl}$ surface had less stable interactions with $\mathrm{H}_{2} \mathrm{O}$ and poorer activity for $\mathrm{H}_{2} \mathrm{O}$ dissociation. To gain additional insight, the structures of the transition state over these two surfaces were further compared (Figure 3b). It can be seen that the absence of $\mathrm{Cl}$ helped to remove the effect of steric hindrance and elongated the $\mathrm{H}$-O bond from 1.40 to $1.44 \AA$ within $\mathrm{H}_{2} \mathrm{O}$, promoting its dissociation. Hence, from the point view of geometric effects, it can be predicted that the absence of $\mathrm{Cl}$ would not only inhibit blockage of the active site but also eliminate the effect of steric hindrance in water dissociation. 
To verify this prediction, the $\mathrm{Cl}$-free monometallic $\mathrm{Ru}$ catalyst, $\mathrm{Ru} / \mathrm{CNT}$, was prepared by using $\mathrm{Ru}(\mathrm{NO})\left(\mathrm{NO}_{3}\right)_{3}$ as the precursor, thus isolating the effects of Co to enable a fair comparison with the $\mathrm{Ru}_{\mathrm{Cl}} / \mathrm{CNT}$ catalyst. As shown in Figure S9, the HAADF-STEM image of the Ru/CNT catalyst exhibited a relatively homogeneous distribution of $\mathrm{Ru}$ particles, the average particle size of which was determined to be $1.34 \pm 0.29 \mathrm{~nm}$. The similar metal particle sizes of the $\mathrm{Ru} / \mathrm{CNT}$ and $\mathrm{Ru} \mathrm{Cl}_{\mathrm{Cl}} / \mathrm{CNT}$ catalysts would help to exclude effects of the $\mathrm{Ru}$ size in this reaction. Moreover, the XPS $\mathrm{Cl} 2 p$ spectra in Figure 3c showed that the $\mathrm{Cl}$-containing $\mathrm{Ru}_{\mathrm{Cl}} / \mathrm{CNT}$ catalyst demonstrates a legible peak with respect to the $\mathrm{Cl}$-free $\mathrm{Ru} / \mathrm{CNT}$ catalyst, indicating the presence of residual surface $\mathrm{Cl}$ species despite $\mathrm{H}_{2}$ reduction. $\mathrm{H}_{2}$-TPR measurements were further conducted to probe the influence of the residual surface $\mathrm{Cl}$ species on the reducibility of $\mathrm{Ru}$ species. As shown in Figure 3d, the $\mathrm{H}_{2}$-TPR profiles were consistent with the above results (Figure S6) in which the $\mathrm{Cl}$-free $\mathrm{Ru} / \mathrm{CNT}$ catalyst exhibited a lower hydrogen reduction peak than the $\mathrm{Cl}$-containing $\mathrm{Ru}_{\mathrm{Cl}} / \mathrm{CNT}$ catalyst, possibly ascribed to the residual surface $\mathrm{Cl}$ inhibiting $\mathrm{Ru}$ reduction.

The as-obtained $\mathrm{Cl}$-free monometallic $\mathrm{Ru} / \mathrm{CNT}$ catalyst was tested for this reaction by using either $\mathrm{H}_{2} \mathrm{O}$ or $\mathrm{D}_{2} \mathrm{O}$ as the reactant. As shown in Figure 3e, the catalyst exhibited a lower reaction rate when using $\mathrm{D}_{2} \mathrm{O}$ as the reactant compared to $\mathrm{H}_{2} \mathrm{O}$. According to the above method, the KIE value for $\mathrm{Ru} / \mathrm{CNT}$ was determined to be 3.15 , compared with that of 3.35 for $\mathrm{Ru}_{\mathrm{Cl}} / \mathrm{CNT}$. The decreased KIE value for $\mathrm{Ru} / \mathrm{CNT}$ is consistent with the above DFT calculations for eliminating site blockage and steric hindrance in water dissociation. Furthermore, the initial catalytic activity of $\mathrm{Ru} / \mathrm{CNT}$ was determined to be $642.8 \mathrm{~mol}_{\mathrm{H} 2} \cdot \mathrm{mol}_{\mathrm{Ru}}{ }^{-1} \cdot \mathrm{min}^{-1}$, which is 3.5-fold higher than that of the $\mathrm{Ru}_{\mathrm{Cl}} / \mathrm{CNT}$ catalyst. Taken together, these findings indicate that the influence of $\mathrm{Cl}$ is mainly attributed to geometric effects, including site blockage and steric hindrance, which are much more significant than the electronic effects of Co, as shown in Figure 2.

\subsection{Maximizing catalytically active sites}

Based on the above analysis, the $\mathrm{Cl}$ geometric effects and Co electronic effects are likely to give rise to the 3.5- and 0.1-fold increment in catalytic activity, respectively, which the geometric effects are much more significant than the electronic effects in terms of $\mathrm{Ru}$ local structure. Hence, for catalyst design, it is highly desirable to further convert the Co electronic effects into geometric effects. Herein, a strategy of acid leaching is proposed to treat the above $\mathrm{Cl}$-free bimetallic Ru-Co catalysts, as shown in Figure 4, with the aim of removing inactive Co sites and creating more edge-like $\mathrm{Ru}$ active sites. The removal of Co atoms creates vacancies on the surface of the metal particles, giving rise to low-coordinated $\mathrm{Ru}$ atoms in the surrounding area. However, it is difficult to predict the effects of low-coordinated $\mathrm{Ru}$ atoms in this reaction. Therefore, a preliminary investigation via DFT calculations was conducted to probe whether the catalytic activity could be promoted by introducing low-coordinated $\mathrm{Ru}$ atoms. 


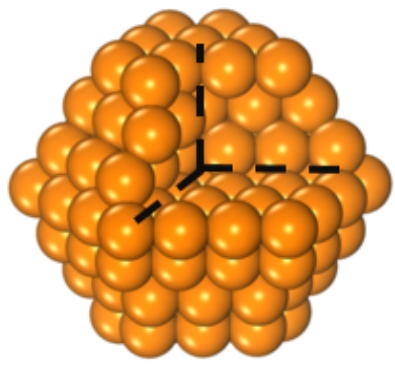

Ru/CNT

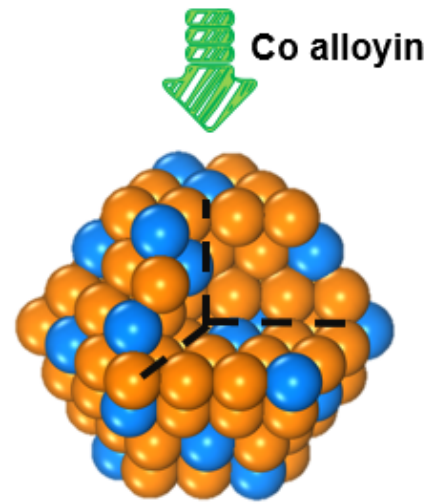

RuCo/CNT
CI removal

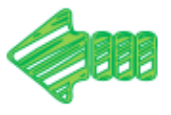

$\mathrm{Ru}_{\mathrm{CI}} / \mathrm{CNT}$

More active sites

Co leaching
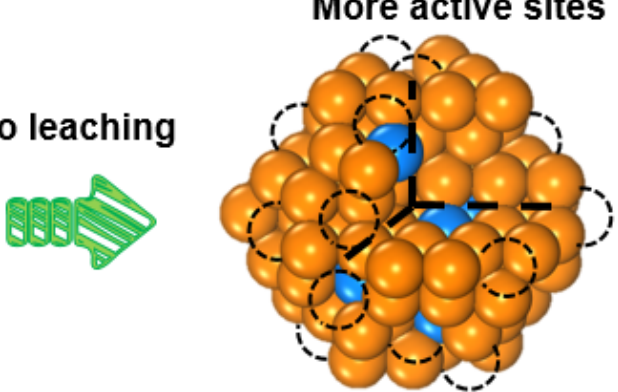

al-RuCo/CNT

Figure 4. The schematic diagram for the preparation of acid-leached al-RuCo/CNT catalyst.

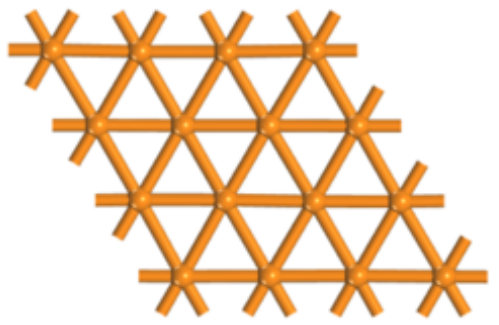

$\mathrm{Ru}(001)$

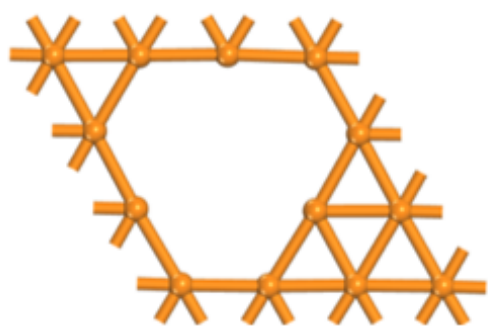

$\mathrm{Ru}(001)$

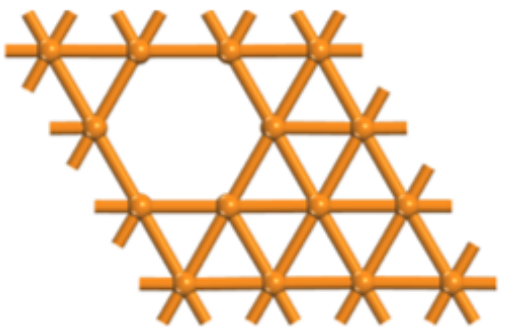

$\mathrm{Ru}(001)-1$

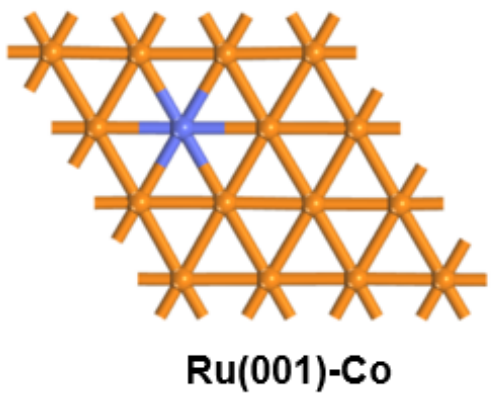


Figure 5. The structure of $\mathrm{Ru}(001), \mathrm{Ru}(001)-1, \mathrm{Ru}(001)-3$, and $\mathrm{Ru}(001)$-Co facets.

To simulate the process of acid leaching, three $(4 \times 4)$ slab models of the typical $\mathrm{Ru}$ facet, $\mathrm{Ru}(001)$, with different vacancy numbers $(0,1$, and 3$)$, i.e., $\mathrm{Ru}(001), \mathrm{Ru}(001)-1$, and $\mathrm{Ru}(001)-3$, were constructed as shown in Figure 5, which the $\mathrm{Ru}(001)$ facet with partial Co replacement, $\mathrm{Ru}(001)$-Co, was also used as a reference. With respect to the $\mathrm{Ru}(001)$ facet, the coordination number of six $\mathrm{Ru}$ atoms within the $\mathrm{Ru}(001)-1$ facet decreased and that of nine $\mathrm{Ru}$ atoms decreased in the $\mathrm{Ru}(001)-3$ facet. Thus, it is reasonable to deduce that the increased Co content within the bimetallic Ru-Co catalyst would contribute to more low-coordinated $\mathrm{Ru}$ sites after the removal of Co. In light of the above analysis on $\mathrm{H}_{2} \mathrm{O}$ dissociation as the prerequisite for $\mathrm{H}_{2}$ production over $\mathrm{Ru}$ catalysts, the energy profiles and corresponding adsorption configurations of the involved species for $\mathrm{H}_{2} \mathrm{O}$ activation over these surfaces were comparatively studied, as shown in Figures $6 \mathrm{a}, 6 \mathrm{~b}$ and S10. The activation barrier for $\mathrm{H}_{2} \mathrm{O}$ dissociation followed a clear trend of $\mathrm{Ru}(001)(0.89 \mathrm{eV})>\mathrm{Ru}(001)-\mathrm{Co}$ $(0.80 \mathrm{eV})>\mathrm{Ru}(001)-1(0.77 \mathrm{eV})>\mathrm{Ru}(001)-3(0.70 \mathrm{eV})$. It can be seen that activation energy decreased with the number of low-coordinated Ru sites. Therefore, based on the DFT calculations, the removal of Co atoms from the bimetallic $\mathrm{RuCo} / \mathrm{CNT}$ catalyst could create more low-coordinated $\mathrm{Ru}$ sites with higher catalytic activity for water dissociation, thus promoting $\mathrm{H}_{2}$ production from ammonia borane.

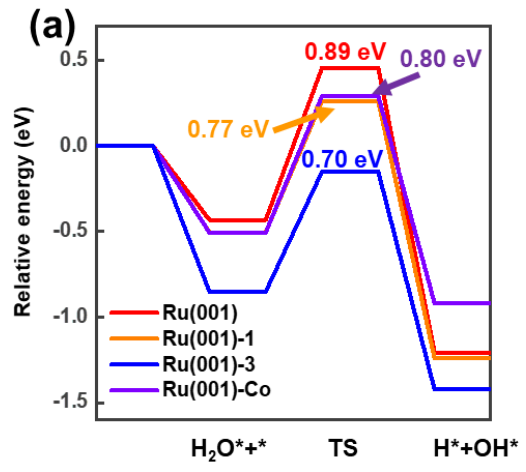

(b)

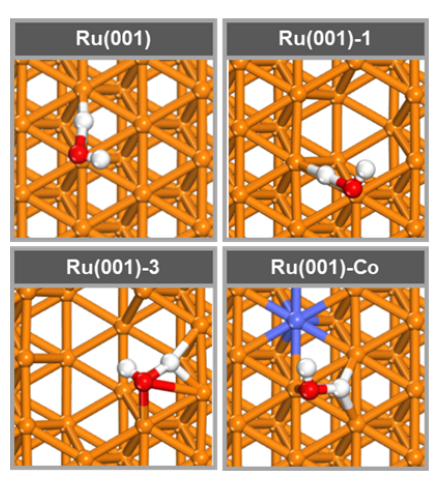

(c)

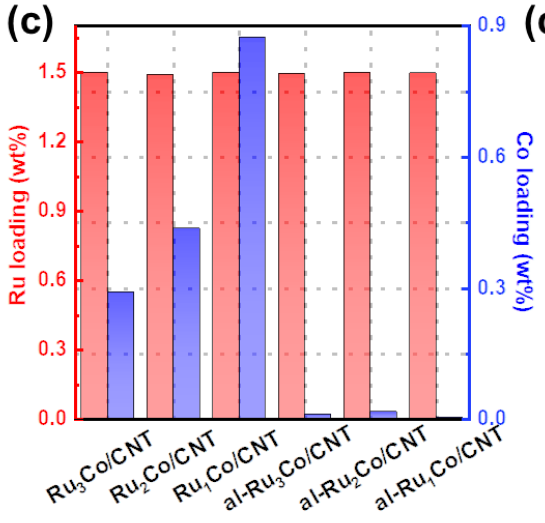

(d)

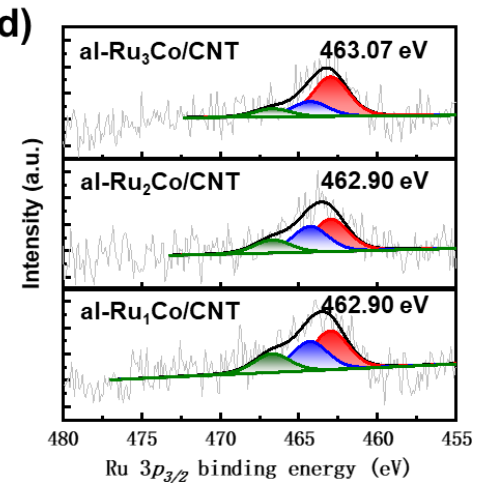

Figure 6. (a) The energy profiles, and (b) corresponding structure of transition states for $\mathrm{H}_{2} \mathrm{O}$ activation 
on the $\mathrm{Ru}(001), \mathrm{Ru}(001)-1, \mathrm{Ru}(001)-3$ and $\mathrm{Ru}(001)$-Co facets. (c) The $\mathrm{Ru}$ and Co loading for the bimetallic $\mathrm{Ru}-\mathrm{Co}$ catalysts before and after acid leaching. (d) The XPS Ru $3 p_{3 / 2}$ spectra of acid-leached al-RuCo/CNT catalysts.

The above findings support the prediction that the removal of Co sites can create more low-coordinated $\mathrm{Ru}$ active sites for this reaction. To further investigate this, dilute $\mathrm{HNO}_{3}(0.01 \mathrm{M})$ was chosen to treat the catalysts to selectively remove Co atoms because concentrated $\mathrm{HNO}_{3}$ may dissolve $\mathrm{Ru}$ atoms. The contents of Ru and Co species in the spent acid solution were measured by ICP. It was found that the contents of Ru in all spent acid solutions were lower than the detection limit. By contrast, the contents of Co in the spent acid solutions varied with the identity of catalyst, based on which the contents of residual Co in the acid-leached catalysts $(\mathrm{al}-\mathrm{RuCo} / \mathrm{CNT})$ were determined as shown in Figure 6a. Nearly all the Co species within the catalysts were dissolved into the acid solution, indicating the successful removal of $\mathrm{Co}$, rather than $\mathrm{Ru}$, for these al-RuCo/CNT catalysts. HAADF-STEM was employed to characterize these catalysts to investigate the influence of acid leaching on the metal particle sizes and distributions. As shown in Figure S11, all catalysts retained a relatively homogeneous distribution of metal particles and were nearly unchanged in size compared to them before the acid leaching treatment. XPS measurement was also conducted to probe changes in the catalysts before and after acid leaching, and the results are shown in Figure 6d. All catalysts clearly exhibited significant increases of $0.3-0.4 \mathrm{eV}$ in the $\mathrm{Ru}$ binding energy after acid leaching. This is consistent with Co transferring electrons to $\mathrm{Ru}$ and the removal of Co lowering the electron density of $\mathrm{Ru}$ to increase its binding energy.

(a)

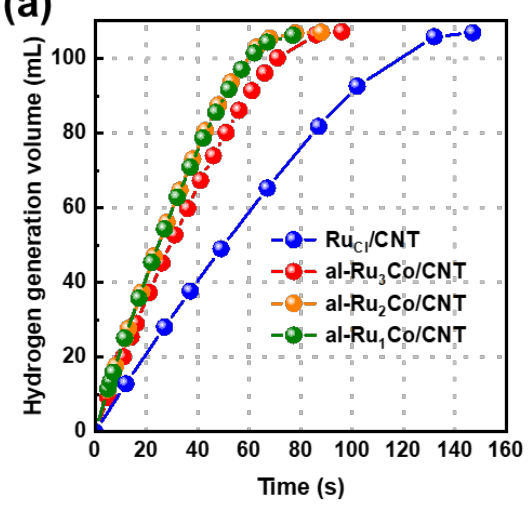

(c)

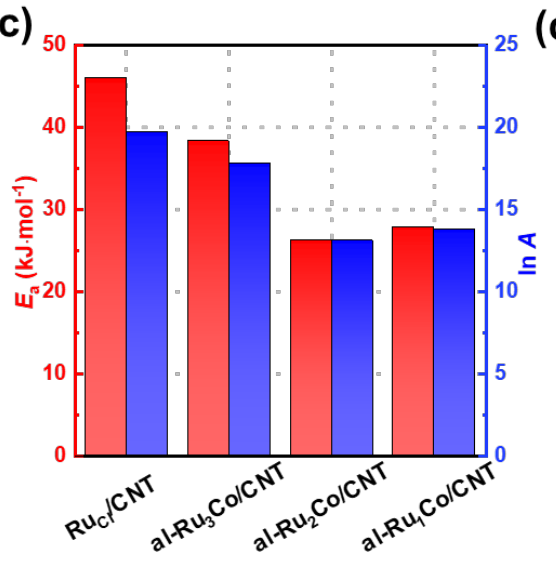

(b)

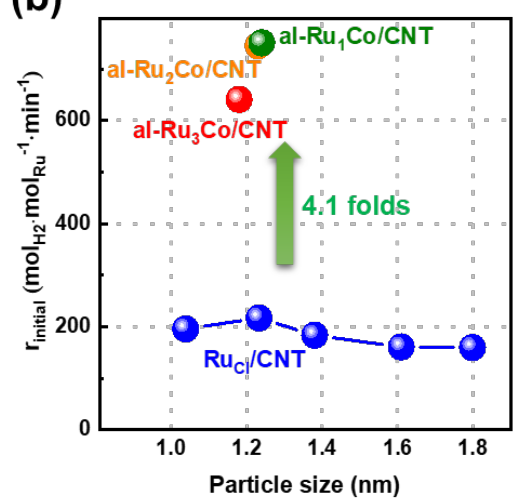

(d)

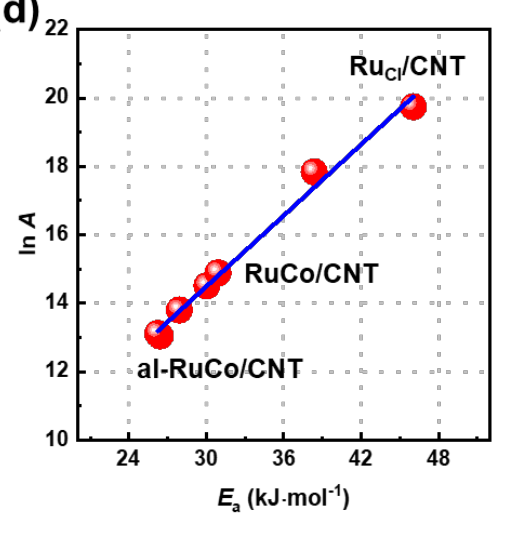

Figure 7. (a) The hydrogen generation volume as a function of reaction time, (b) the initial catalytic activity $\left(\mathrm{r}_{\text {initial }}\right),(\mathrm{c})$ the activation energy $\left(E_{a}\right)$ and logarithm of pre-exponential factor $(\ln A)$ for the

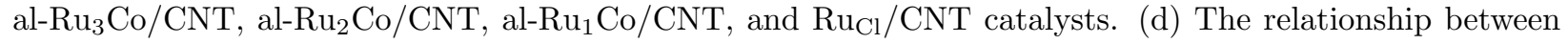


activation energy $\left(E_{a}\right)$ and the logarithm of pre-exponential factor $(\ln A)$ of the above catalysts. The Ru loading for $\mathrm{Ru}_{\mathrm{Cl}} / \mathrm{CNT}$ catalyst was $1.5 \mathrm{wt} \%$.

The acid-leached catalysts were tested for this reaction under the same reaction conditions, and the results are shown in Figure 7a. All catalysts still retained zero-order kinetics at the initial stage of the reaction, and the initial catalytic activity $\left(\mathrm{r}_{\text {initial }}\right)$ was further calculated as shown in Figure $7 \mathrm{~b}$. As expected, all catalysts demonstrated a sharp increase in catalytic activity. Notably, the highest hydrogen generation of $751.0 \mathrm{~mol}_{\mathrm{H} 2} \cdot \mathrm{mol}_{\mathrm{Ru}}{ }^{-1} \cdot \mathrm{min}^{-1}$ was achieved for the al- $\mathrm{Ru}_{1} \mathrm{Co} / \mathrm{CNT}$ catalyst, which was almost 4.1-fold higher than that of the $\mathrm{Ru}_{\mathrm{Cl}} / \mathrm{CNT}$ catalyst. Kinetic experiments over the temperature range from 25 to $40{ }^{\circ} \mathrm{C}$ were also performed, as shown in Figure S12. Similarly, the reaction rate constants at different temperatures could be calculated, which further yielded the activation energy $\left(E_{a}\right)$ and the logarithm of pre-exponential factor $(\ln A)$. Figure $7 \mathrm{c}$ shows that both $E_{a}$ and $\ln A$ decreased with the Co content within the bimetallic $\mathrm{RuCo} / \mathrm{CNT}$ catalyst before acid leaching. This is consistent with the above DFT calculations showing that the more low-coordinated $\mathrm{Ru}$ sites after acid leaching, the lower the activation energy for the kinetically relevant step of water dissociation.

Furthermore, it is found that the kinetics parameters $E_{a}$ and $\ln A$ demonstrated a remarkable kinetic compensation effect, as shown in Figure 7d, which followed the Cremer-Constable relation of a linear dependence of $\ln A$ on $E_{a}{ }^{45,46}$. This compensation effect could be divided into three kinetics regimes: the al-RuCo/CNT, $\mathrm{RuCo} / \mathrm{CNT}$, and $\mathrm{Ru}_{\mathrm{Cl}} / \mathrm{CNT}$ catalysts located in the regimes of low, medium and high $E_{a}$ and $\ln A$ values, respectively. In light of the previous DFT study, this could be interpreted as the change in the binding strength of reaction species, which induces a switch in the kinetic regime. Specifically, the adsorption of reactants could be weak for the $\mathrm{Cl}$-containing $\mathrm{Ru}_{\mathrm{Cl}} / \mathrm{CNT}$ catalyst due to site blockage and steric hindrance. Upon the removal of $\mathrm{Cl}$ and the introduction of low-coordinated $\mathrm{Ru}$ active sites, the reaction switches from a $\mathrm{Cl}$ coverage-limited regime to a reactant activation regime, giving rise to al-RuCo/CNT catalysts with lower activation energies that have higher catalytic activity. Hence, combining the DFT calculations, multiple characterizations, and kinetic analyses allow the conclusion that the presence of abundant low-coordinated $\mathrm{Ru}$ sites after acid leaching contribute to a significantly increased quantity and quality of Ru active sites, thereby boosting the catalytic activity of al- $\mathrm{Ru}_{1} \mathrm{Co} / \mathrm{CNT}$. The mechanistic insights gained through this study may serve as a foundation for fine-tuning the metal local structure to achieve enhanced reaction kinetics.

\section{Conclusions}

In summary, we demonstrated a strategy for engineering $\mathrm{Ru}$ local structures via the employment of a $\mathrm{Cl}-$ free $\mathrm{Ru}$ precursor and the acid leaching of bimetallic $\mathrm{Ru}$-Co catalysts, toward more active site with high mass-specific activity for hydrogen generation from ammonia borane hydrolysis. The roles of $\mathrm{Cl}$ and $\mathrm{Co}$ were separately investigated by comparing Cl-free/Cl-containing monometallic Ru catalysts and Co-leaching/Cocontaining bimetallic Ru-Co catalysts, respectively. A combination of multiple characterization techniques, kinetic (isotopic) analyses, and DFT calculations suggests that the influences of $\mathrm{Cl}$ and Co are mainly attributed to geometric effects (site blockage and steric hindrance) and electronic effects (electron transfer from $\mathrm{Co}$ to $\mathrm{Ru}$ ), respectively. Decoupled from other factors, the $\mathrm{Ru}$ geometric effects were identified as the main factor for improving the hydrogen generation rate, which could be further promoted by acid leaching to introduce more low-coordinated Ru sites. It is found that the quantity of edge-like Ru active sites increased with the Co content in bimetallic $\mathrm{Ru}$-Co catalysts, giving rise to a significantly lower activation barrier for water dissociation. As a result, the acid-leached al- $\mathrm{Ru}_{1}$ Co catalyst with the increased quantity and quality of $\mathrm{Ru}$ active sites delivered a substantial 4.1-fold increase in catalytic activity. The strategy developed here may shed new light on the design and fabrication of metal catalysts with the maximum active sites for this reaction.

\section{Acknowledgments}

This work was financially supported by the Natural Science Foundation of China (21922803 and 21776077), the China Postdoctoral Science Foundation (BX20190116), the Program for Professor of Special Appointment (Eastern Scholar) at Shanghai Institutions of Higher Learning, the State Key Laboratory of Organic- 
Inorganic Composites (oic-201801007), 111 Project of the Ministry of Education of China (B08021) and the Open Project of State Key Laboratory of Chemical Engineering (SKLChe-15C03). Mr. Wenzhao Fu gratefully acknowledged financial support from China Scholarship Council (No. 201906745022).

\section{References}

[1] Gu X, Lu ZH, Jiang HL, Akita T, Xu Q. Synergistic catalysis of metal-organic framework-immobilized $\mathrm{Au}-\mathrm{Pd}$ nanoparticles in dehydrogenation of formic acid for chemical hydrogen storage. J Am Chem Soc. 2011;133:11822-11825.

[2] Turner JA. Sustainable hydrogen production. Science. 2004;305:972-974.

[3] Zuttel A. Materials for hydrogen storage. Mater Today. 2003;6:24-33.

[4] Rosi NL, Eckert J, Eddaoudi M, Vodak DT, Kim J, O'Keeffe M, Yaghi OM. Hydrogen storage in microporous metal-organic frameworks. Science. 2003;300:1127-1129.

[5] Murray LJ, Dinca M, Long JR. Hydrogen storage in metal-organic frameworks. Chem Soc Rev. 2009;38:1294-1314.

[6] Staubitz A, Robertson AP, Manners I. Ammonia-borane and related compounds as dihydrogen sources. Chem Rev. 2010;110:4079-4124.

[7] Marder TB. Will we soon be fueling our automobiles with ammonia-borane? Angew Chem Int Ed. 2007;46:8116-8118.

[8] Metin O, Mazumder V, Ozkar S, Sun S. Monodisperse nickel nanoparticles and their catalysis in hydrolytic dehydrogenation of ammonia borane. J Am Chem Soc. 2010;132:1468-1469.

[9] Metin O, Ozkar S, Sun S. Monodisperse nickel nanoparticles supported on $\mathrm{SiO}_{2}$ as an effective catalyst for the hydrolysis of ammonia-borane. Nano Re. 2010;3:676-684.

[10] Jiang HL, Xu Q. Catalytic hydrolysis of ammonia borane for chemical hydrogen storage. Catal Today. 2011;170:56-63.

[11] Peng B, Chen J. Ammonia borane as an efficient and lightweight hydrogen storage medium. Energ Environ Sci. 2008;1:479-483.

[12] Li Z, He T, Matsumura D, Miao S, Wu A, Liu L, Wu G, Chen P. Atomically dispersed Pt on the surface of Ni particles: synthesis and catalytic function in hydrogen generation from aqueous ammonia-borane. ACS Catal. 2017;7:6762-6769.

[13] Demirci UB. Ammonia borane, a material with exceptional properties for chemical hydrogen storage. Int J Hydrogen Energ. 2017;42:9978-10013.

[14] Diwan M, Hwang HT, Al-Kukhun A, Varma A. Hydrogen generation from noncatalytic hydrothermolysis of ammonia borane for vehicle applications. AIChE J. 2011;57:259-264.

[15] Hwang HT, Greenan P, Kim SJ, Varma A. Effect of boric acid on thermal dehydrogenation of ammonia borane: $\mathrm{H}_{2}$ yield and process characteristics. AIChE J. 2013;59:3359-3364.

[16] Sanyal U, Demirci UB, Jagirdar BR, Miele P. Hydrolysis of ammonia borane as a hydrogen source: fundamental issues and potential solutions towards implementation. ChemSusChem. 2011;4:1731-1739.

[17] Demirci UB, Miele P. Sodium borohydride versus ammonia borane, in hydrogen storage and direct fuel cell applications. Energ Environ Sci. 2009;2:627-637.

[18] Xu Q, Chandra M. A portable hydrogen generation system: catalytic hydrolysis of ammonia-borane. J Alloy Compd. 2007;446:729-732. 
[19] Zhan WW, Zhu QL, Xu Q. Dehydrogenation of ammonia borane by metal nanoparticle catalysts. ACS Catal. 2016;6:6892-6905.

[20] Chen W, Ji J, Duan X, Qian G, Li P, Zhou X, Chen D, Yuan W. Unique reactivity in Pt/CNT catalyzed hydrolytic dehydrogenation of ammonia borane. Chem Commun. 2014;50:2142-2144.

[21] Khalily MA, Eren H, Akbayrak S, Susapto HH, Biyikli N, Ozkar S, Guler MO. Facile synthesis of three-dimensional $\mathrm{Pt}-\mathrm{TiO}_{2}$ nano-networks: A highly active catalyst for the hydrolytic dehydrogenation of ammonia-borane. Angew Chem. 2016;128:12445-12449.

[22] Mori K, Miyawaki K, Yamashita H. Ru and Ru-Ni nanoparticles on $\mathrm{TiO}_{2}$ support as extremely active catalysts for hydrogen production from ammonia-borane. ACS Catal. 2016;6:3128-3135.

[23] Yao Q, Shi W, Feng G, Lu ZH, Zhang X, Tao D, Kong D, Chen X. Ultrafine Ru nanoparticles embedded in $\mathrm{SiO}_{2}$ nanospheres: highly efficient catalysts for hydrolytic dehydrogenation of ammonia borane. J Power Sources. 2014;257:293-299.

[24] Chen G, Desinan S, Rosei R, Rosei F, Ma D. Synthesis of Ni-Ru alloy nanoparticles and their high catalytic activity in dehydrogenation of ammonia borane. Chem-Eur J. 2012;18:7925-7930.

[25] Cao N, Su J, Luo W, Cheng G. Hydrolytic dehydrogenation of ammonia borane and methylamine borane catalyzed by graphene supported Ru@ Ni core-shell nanoparticles. Int J Hydrogen Energ. 2014;39:426-435.

[26] Bhunya S, Roy L, Paul A. Mechanistic details of Ru-bis (pyridyl) borate complex catalyzed dehydrogenation of ammonia-borane: role of the pendant boron ligand in catalysis. ACS Catal. 2016;6:4068-4080.

[27] Käß M, Friedrich A, Drees M, Schneider S. Ruthenium complexes with cooperative PNP ligands: bifunctional catalysts for the dehydrogenation of ammonia-borane. Angew Chem Int Ed. 2009;48:905-907.

[28] Cao N, Luo W, Cheng G. One-step synthesis of graphene supported Ru nanoparticles as efficient catalysts for hydrolytic dehydrogenation of ammonia borane. Int J Hydrogen Energ. 2013;38:11964-11972.

[29] Akbayrak S, Tonbul Y, Ozkar S. Ceria-supported ruthenium nanoparticles as highly active and long-lived catalysts in hydrogen generation from the hydrolysis of ammonia borane. Dalton Trans. 2016;45:10969-10978.

[30] Yao Q, Lu ZH, Yang K, Chen X, Zhu M. Ruthenium nanoparticles confined in SBA-15 as highly efficient catalyst for hydrolytic dehydrogenation of ammonia borane and hydrazine borane. Sci Rep. 2015;5:15186.

[31] Song Q, Wang WD, Hu X, Dong Z. Ru nanoclusters confined in porous organic cages for catalytic hydrolysis of ammonia borane and tandem hydrogenation reaction. Nanoscale. 2019;11:21513-21521.

[32] Chen W, Ji J, Feng X, Duan X, Qian G, Li P, Zhou X, Chen D, Yuan W. Mechanistic insight into sizedependent activity and durability in Pt/CNT catalyzed hydrolytic dehydrogenation of ammonia borane. J Am Chem Soc. 2014;136:16736-16739.

[33] Feng X, Duan X, Qian G, Zhou X, Chen D, Yuan W. Insights into size-dependent activity and active sites of $\mathrm{Au}$ nanoparticles supported on TS-1 for propene epoxidation with $\mathrm{H}_{2}$ and $\mathrm{O}_{2}$. J Catal. 2014;317:99-104.

[34] Fu W, Chen W, Qian G, Chen D, Yuan W, Zhou X, Duan X. Kinetics-assisted discrimination of active sites in Ru catalyzed hydrolytic dehydrogenation of ammonia borane. React Chem Eng. 2019;4:316-322.

[35] Kresse G, Hafner J. Ab initio molecular dynamics for liquid metals. Phys Rev B. 1993;47:558.

[36] Kresse G, Hafner J. Ab initio molecular-dynamics simulation of the liquid-metal-amorphoussemiconductor transition in germanium. Phys Rev B. 1994;49:14251.

[37] Kresse G, Furthmüller J. Efficiency of ab-initio total energy calculations for metals and semiconductors using a plane-wave basis set. Comp Mater Sci. 1996;6:15-50.

[38] Kresse G, Furthmuller J. Efficient iterative schemes for ab initio total-energy calculations using a planewave basis set. Phys Rev B. 1996;54:11169. 
[39] Blochl PE. Projector augmented-wave method. Phys Rev B. 1994;50:17953.

[40] Perdew JP, Burke K, Ernzerhof M. Generalized gradient approximation made simple. Phys Rev Lett. $1996 ; 77: 3865$.

[41] Monkhorst HJ, Pack JD. Special points for Brillouin-zone integrations. Phys Rev B. 1976;13:5188.

[42] Ma H, Na C. Isokinetic temperature and size-controlled activation of ruthenium-catalyzed ammonia borane hydrolysis. ACS Catal. 2015;5:1726-1735.

[43] Chen W, Li D, Peng C, Qian G, Duan X, Chen D, Zhou X. Mechanistic and kinetic insights into the Pt-Ru synergy during hydrogen generation from ammonia borane over PtRu/CNT nanocatalysts. J Catal. 2017;356:186-196.

[44] Teschner D, Novell-Leruth G, Farra R, Knop-Gericke A, Schlogl R, Szentmiklosi L, Hevia MG, Soerijanto $\mathrm{H}$, Schomacker R, Perez-Ramirez J, Lopez N. In situ surface coverage analysis of $\mathrm{RuO}_{2}$-catalysed $\mathrm{HCl}$ oxidation reveals the entropic origin of compensation in heterogeneous catalysis. Nat Chem. 2012;4:739-745.

[45] Bond GC, Keane MA, Kral H, Lercher JA. Compensation phenomena in heterogeneous catalysis: general principles and a possible explanation. Catal Rev. 2000;42:323-383.

[46] Andreasen A, Vegge T, Pedersen AS. Compensation effect in the hydrogenation/dehydrogenation kinetics of metal hydrides. J Phys Chem B. 2005;109:3340-3344. 